\title{
Validation of the German Classification of Diverticular Disease (VADIS)—a prospective bicentric observational study
}

\author{
Johannes C. Lauscher ${ }^{1}$ (D) - Johan F. Lock ${ }^{2} \cdot$ Katja Aschenbrenner $^{1} \cdot$ Rahel M. Strobel $^{1} \cdot$ Marja Leonhardt $^{3}$. \\ Andrea Stroux ${ }^{4,5} \cdot$ Benjamin Weixler ${ }^{1} \cdot$ Christoph-Thomas Germer $^{2} \cdot$ Martin E. Kreis ${ }^{1}$
}

Accepted: 21 August 2020 / Published online: 4 September 2020

(C) The Author(s) 2020

\begin{abstract}
Purpose The German Classification of Diverticular Disease was introduced a few years ago. The aim of this study was to determine whether Classification of Diverticular Disease enables an exact stratification of different types of diverticular disease in terms of course and treatment.

Methods This was a prospective, bicentric observational trial. Patients aged $\geq 18$ years with diverticular disease were prospectively included. The primary endpoint was the rate of recurrence within 2 year follow-up. Secondary outcome measures were Gastrointestinal Quality of Life Index, Quality of life measured by SF-36, frequency of gastrointestinal complaints, and postoperative complications. Results A total of 172 patients were included. After conservative management, $40 \%$ of patients required surgery for recurrence in type $1 \mathrm{~b}$ vs. $80 \%$ in type $2 \mathrm{a} / \mathrm{b}(p=0.04)$. Sixty percent of patients with type $2 \mathrm{a}$ (micro-abscess) were in need of surgery for recurrence vs. $100 \%$ of patients with type $2 \mathrm{~b}$ (macro-abscess) $(p=0.11)$. Patients with type $2 \mathrm{a}$ reached $123 \pm 15$ points in the Gastrointestinal Quality of Life Index compared with $111 \pm 14$ in type $2 b(p=0.05)$ and higher scores in the "Mental Component Summary" scale of SF-36 (52 \pm 10 vs. $43 \pm 13 ; p=0.04$ ). Patients with recurrent diverticulitis without complications (type 3b) had less often painful constipation $(30 \%$ vs. $73 \% ; p=0.006)$ when they were operated compared with conservative treatment. Conclusion Differentiation into type $2 \mathrm{a}$ and $2 \mathrm{~b}$ based on abscess size seems reasonable as patients with type $2 \mathrm{~b}$ required surgery while patients with type 2 a may be treated conservatively. Sigmoid colectomy in patients with type $3 \mathrm{~b}$ seems to have gastrointestinal complaints during long-term follow-up.
\end{abstract}

Trial registration https://www.drks.de ID: DRKS00005576

Keywords Diverticular disease $\cdot$ Classification $\cdot$ Prospective trial $\cdot$ Surgical treatment Conservative treatment $\cdot$ Recurrence . Quality of life

Johannes C. Lauscher, Johan F. Lock, Christoph-Thomas Germer and Martin E. Kreis contributed equally to this work.

Johannes C. Lauscher

johannes.lauscher@charite.de

Johan F. Lock

lock_J@ukw.de

Katja Aschenbrenner

katja.aschenbrenner@charite.de

Rahel M. Strobel

rahel-strobel@charite.de

Marja Leonhardt

marja.leonhardt@sykehuset-innlandet.no

\author{
Andrea Stroux \\ andrea.stroux@charite.de \\ Benjamin Weixler \\ benjamin.weixler@charite.de \\ Christoph-Thomas Germer \\ germer_C@ukw.de \\ Martin E. Kreis \\ martin.kreis@charite.de
}

Extended author information available on the last page of the article 


\section{Introduction}

The prevalence of diverticulosis and diverticular disease (DD) is rising in the western population. It is associated with increasing age-approximately $5 \%$ of the population under the age of 40 suffer from diverticulosis or DD and up to $65 \%$ of people aged 65 or more [1]. Patients with diverticulosis suffer from acute diverticulitis in $10-25 \%$ in the course of their lifetime. Another 15-20\% with acute diverticulitis develop complications such as perforation, abscess, fistula, or stenosis [2].

In the last three decades, many classifications of DD were introduced, namely Hinchey [3] and modified Hinchey [4]. The internationally used modified Hinchey classification provides a detailed analysis of perforated diverticulitis irrespective of the abscess size and does not include uncomplicated and chronic recurrent types of diverticular disease [4].

These classifications have their limitations. The Classification of Diverticular Disease (CDD) as a more complex classification was introduced in Germany in 2014 (Table 1) [5-7]. CDD differentiates between acute uncomplicated phlegmonous diverticulitis without abscess (type 1b), and different types of acute complicated DDcovered perforation with micro-abscess $\leq 1 \mathrm{~cm}$ (type 2a), covered perforation with macro-abscess $>1 \mathrm{~cm}$ (type $2 \mathrm{~b}$ ), and free perforation (type 2c). According to the German CDD guideline, type 2 a may be treated conservatively with antibiotics and does not require surgery in most cases, and type $2 \mathrm{~b}$ is normally treated with antibiotics, percutaneous drainage when feasible, and elective sigmoid colectomy [6]. The CDD lists three types of chronic DD (relapsing or persistent symptomatic diverticular disease) - namely type $3 \mathrm{a}$ as symptomatic uncomplicated $\mathrm{DD}$, type $3 \mathrm{~b}$ as relapsing diverticulitis without complications, and type $3 \mathrm{c}$ with complications such as colonic stenoses, fistulas, or inflammatory mass.

The hypothesis of the prospective bicentered observational VADIS trial (Validation of the Classification of Diverticular Disease) was that CDD classifies diverticulitis with phlegmonous peridiverticulitis correctly as acute uncomplicated DD in terms of need for surgery, rate of recurrence, and long-term quality of life in comparison with acute complicated DD with micro-abscess and macro-abscess. We hypothesized that type $2 \mathrm{a}$ and type $2 \mathrm{~b}$ differ regarding the shortterm and long-term courses and, in addition, that relapsing diverticulitis without complications and with complications has different short-term and long-term outcomes. Accordingly, we hypothesized that types $1 \mathrm{~b}$ and $2 \mathrm{a}$ do not generally benefit from sigmoid colectomy, while type $2 b$ has a better outcome after surgery.

\section{Method}

\section{Trial oversight}

VADIS was a bicentric, prospective observational trial. Patients with proven DD were prospectively included and follow-up was conducted 1 and 2 years after inclusion.

The study protocol was approved by the Ethics Committee of the Charite - University Medicine Berlin (Application No. EA4/092/13). The trial was conducted in accordance with the ethical principles of the Declaration of Helsinki and the principles of Good Clinical Practice (ICH-GCP E6) [8]. The VADIS trial is registered at "Deutsches Register Klinischer Studien" https://www.drks.de (ID: DRKS00005576) and reported according to STROBE statement [9].

\section{Patients and therapeutic strategy}

Patients 18 years or older, capable to give informed consent, and suffering from diverticular disease (DD) were eligible to participate. Types $3 \mathrm{a}$ (symptomatic uncomplicated diverticular disease) and type 4 (diverticular bleeding) were excluded because these are distinct disease entities. DD was proven clinically (abdominal pain AND increase in white blood cell count $>11 / \mathrm{nl}$ OR increase in C-reactive protein $>5 \mathrm{mg} / \mathrm{dl}$ ) and confirmed in spiral computerized abdominal tomography scan. The diagnostic criteria in cross-sectional imaging were direct proof of inflamed diverticula, bowel wall thickening $>3$ $\mathrm{mm}$, increased contrast enhancement, perifocal mesenteric injection, or free abdominal fluid according to recent guidelines for DD [5, 7]. All patients were classified according to CDD (Table 1). For representative images of different types of diverticular disease, see Fig. 1a-e.

Patients were enrolled by one of the surgeons involved in the trial. All patients were clinically examined and a blood sample was taken. Health-related quality of life was assessed at the time of inclusion using the validated questionnaires Gastrointestinal Quality of Life Index (GIQLI) [10] and Short Form 36 Health Survey (SF-36) [11].

Patients were treated according to the German CDD (Fig. 2) [5-7]. Conservative treatment was defined as admission to ward, intravenous antibiotic treatment, and, if necessary, insertion of percutaneous abscess drainage by interventional radiology. A percutaneous abscess drainage was inserted in patients with macro-abscess when technically feasible. Antibiotic treatment included cefuroxime (M.P.I. Pharmaceutica, Hamburg, Germany) - three times per day $1.5 \mathrm{~g}$ intravenously - and metronidazole (Braun, Bethlehem, USA) - three times per day $500 \mathrm{mg}$ intravenously. Initial/ primary surgical treatment was defined as sigmoid resection including the upper third of the rectum either during the initial 
Table 1 Classification of Diverticular Disease (CDD) [6]

\begin{tabular}{|c|c|c|}
\hline Type 0 & Asymptomatic diverticulosis & Random finding; asymptomatic \\
\hline Type 1 & Acute uncomplicated diverticular disease/diverticulitis & \\
\hline Type 1a & Diverticulitis/diverticular disease without peridiverticulitis & $\begin{array}{l}\text { Symptoms attributable to diverticula } \\
\text { Signs of inflammation (lab tests): optional Typical cross-sectional imaging }\end{array}$ \\
\hline Type $1 b$ & Diverticulitis with phlegmonous peridiverticulitis & $\begin{array}{l}\text { Signs of inflammation (lab tests): mandatory } \\
\text { Cross-sectional imaging: phlegmonous peridiverticulitis }\end{array}$ \\
\hline Type 2 & $\begin{array}{l}\text { Acute complicated diverticulitis } \\
\text { As } 1 \mathrm{~b} \text {, plus: }\end{array}$ & \\
\hline Type 2a & Micro-abscess & Covered perforation, small abscess $(\leq 1 \mathrm{~cm})$; minimal paracolic air \\
\hline Type $2 b$ & Macro-abscess & Paracolic or mesocolic abscess $(>1 \mathrm{~cm})$ \\
\hline Type 2c & Free perforation & $\begin{array}{l}\text { Free perforation, free air/fluid } \\
\text { Generalized peritonitis }\end{array}$ \\
\hline Type $2 \mathrm{c} 1$ & Purulent peritonitis & \\
\hline Type $2 \mathrm{c} 2$ & Fecal peritonitis & \\
\hline Type 3 & $\begin{array}{l}\text { Chronic diverticular disease } \\
\text { Relapsing or persistent symptomatic diverticular disease }\end{array}$ & \\
\hline Type $3 \mathrm{a}$ & Symptomatic uncomplicated diverticular disease & $\begin{array}{l}\text { Typical clinical features } \\
\text { Signs of inflammation (lab tests): optional }\end{array}$ \\
\hline Type $3 b$ & Relapsing diverticulitis without complications & $\begin{array}{l}\text { Signs of inflammation (lab tests): present } \\
\text { Cross-sectional imaging: typical }\end{array}$ \\
\hline Type 3c & Relapsing diverticulitis with complications & Identification of stenoses, fistulas, conglomerate tumors \\
\hline Type 4 & Diverticular bleeding & Identification of source of bleeding \\
\hline
\end{tabular}

stay or within 8 weeks after the first admission. According to the CDD guideline, the initial surgical treatment was recommended in type $2 b$ (acute diverticulitis with macro-abscess), type $2 \mathrm{c}$ (free perforation), and type $3 \mathrm{c}$ (chronic recurrent diverticulitis with complications). Types $1 \mathrm{~b}$ and $2 \mathrm{a}$ were only operated initially if patients suffered from persistent symptoms. In patients with type $3 b$ (chronic recurrent diverticulitis without complications), an individual decision was made depending on the frequency and severity of diverticulitis episodes, comorbidities, and age. Sigmoid colectomy was performed in a standardized fashion. The period of hospitalization including readmission due to postoperative complications was documented 30 days postoperatively.

\section{Outcomes}

The primary endpoint was the recurrence of DD within a 2 year follow-up. The previously described criteria for DD were again required for the diagnosis of recurrence. Treatment of a recurrent episode was assessed as regards outpatient treatment, admission to hospital, and conservative or surgical treatment with potential postoperative complications.

Secondary endpoints were as follows:

1. Frequency of gastrointestinal symptoms after 2 years. Persistent abdominal pain, bloating, and painful constipation were measured by a questionnaire with 5-point Likert scale.
2. Gastrointestinal Quality of Life Index (GIQLI) after 2 years with an evaluation of the total score of the questionnaire as described previously.

3. Health-related quality of life measured by the Short Form 36 Health Survey (SF-36) questionnaire after 2 years.

4. Postoperative complications during the primary stay and early elective interval or surgery due to the recurrence of DD. Relaparotomy was defined as an unplanned laparotomy due to a postoperative complication within 30 days after sigmoid resection.

Data were collected on paper-based case report forms at the time of recruitment (visit 1), directly after surgery during the primary stay and early elective interval (visit 2), 30 days after the operation (visit 3), 1 year (visit 4), and 2 years (visit 5) after the episode of DD leading to inclusion in VADIS. Follow-up after 1 and 2 years was conducted by telephone interview.

\section{Statistical analysis}

The primary endpoint recurrence was analyzed with crosstabulation and chi-square test. Frequency of gastrointestinal symptoms, subgroup analysis of CDD and association between recurrence of DD and health-related quality of life after 2 years, and primary treatment were also assessed by crosstabulation and chi-square test. For quantitative outcomes such as the secondary parameters GIQLI and SF-36, statistical 
Fig. 1 CT images illustrating different types of diverticular disease according to CDD. CDD type $1 \mathrm{~b}$ in axial (a) and coronal (b) view. Asterisks mark inflamed diverticula. White arrows show phlegmonous inflammation of pericolic tissue (fat tissue stranding). c CDD type 2a with phlegmonous inflammation of pericolic tissue plus microabscess $(0.9 \mathrm{~cm})$ marked by a white arrow as a sign of covered perforation. $\mathbf{d}$ CDD type $2 \mathrm{~b}$ with phlegmonous inflammation of pericolic tissue plus pericolic macro-abscess $(5 \times 1.5 \mathrm{~cm})$ marked by a white arrow as a sign of covered perforation. e CDD type $3 b$ with radiologic signs of chronic recurrent inflammation with thickening of the colonic wall, luminal narrowing, and multiple non-irritated diverticula (marked by white arrow)
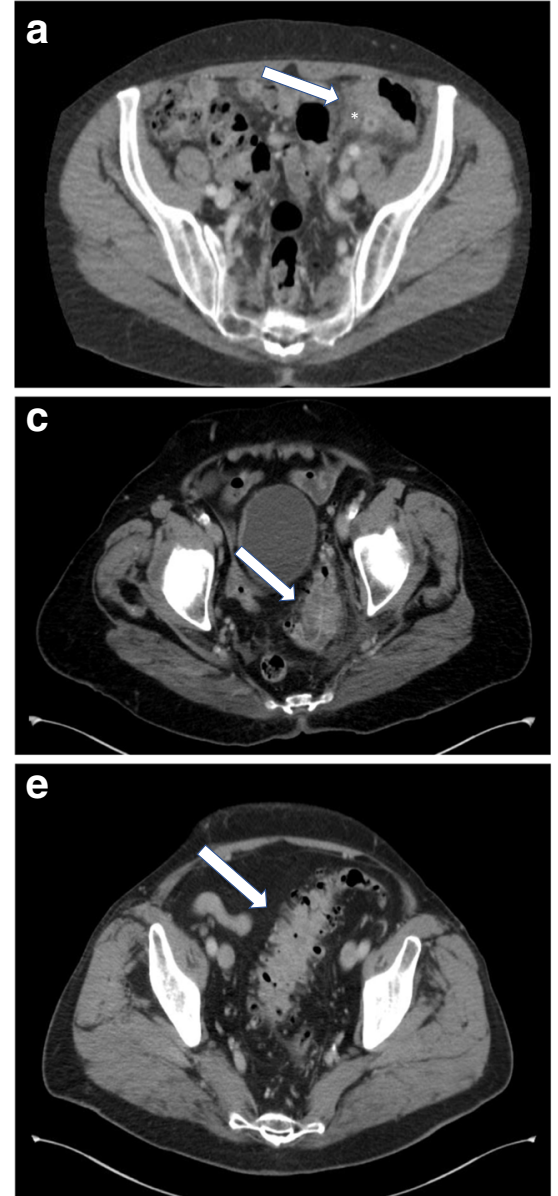

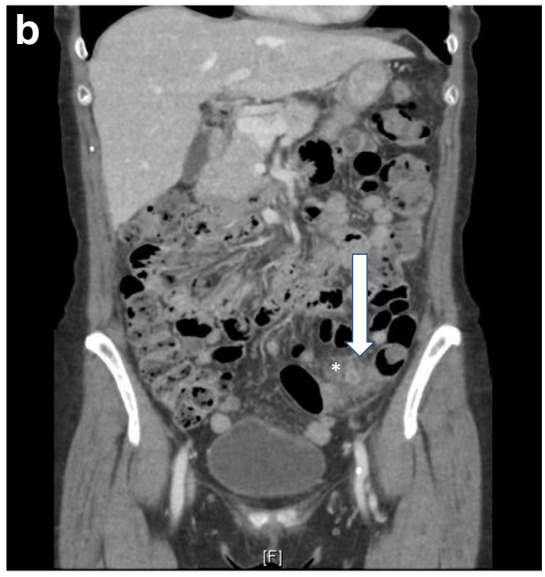

d

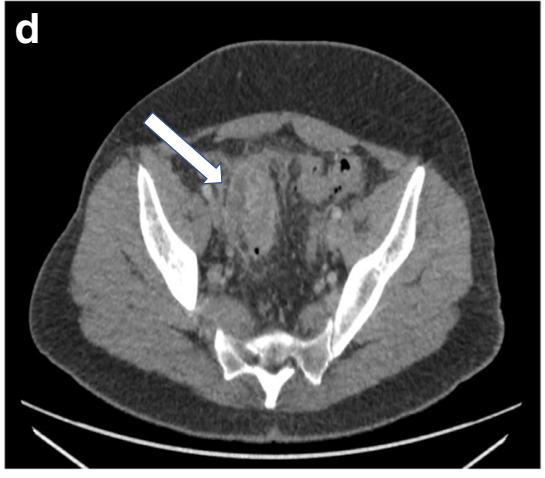

group comparisons were performed using the $t$ test for independent variables. Additional parameters were depicted according to their scale and distribution with absolute and relative frequencies for categorical parameters and mean and standard deviation for quantitative parameters. $p$ values $\leq$ 0.05 were considered statistically significant. Statistical analysis was carried out using IBM SPSS Statistics 25® (IBM, Armonk, NY, USA).

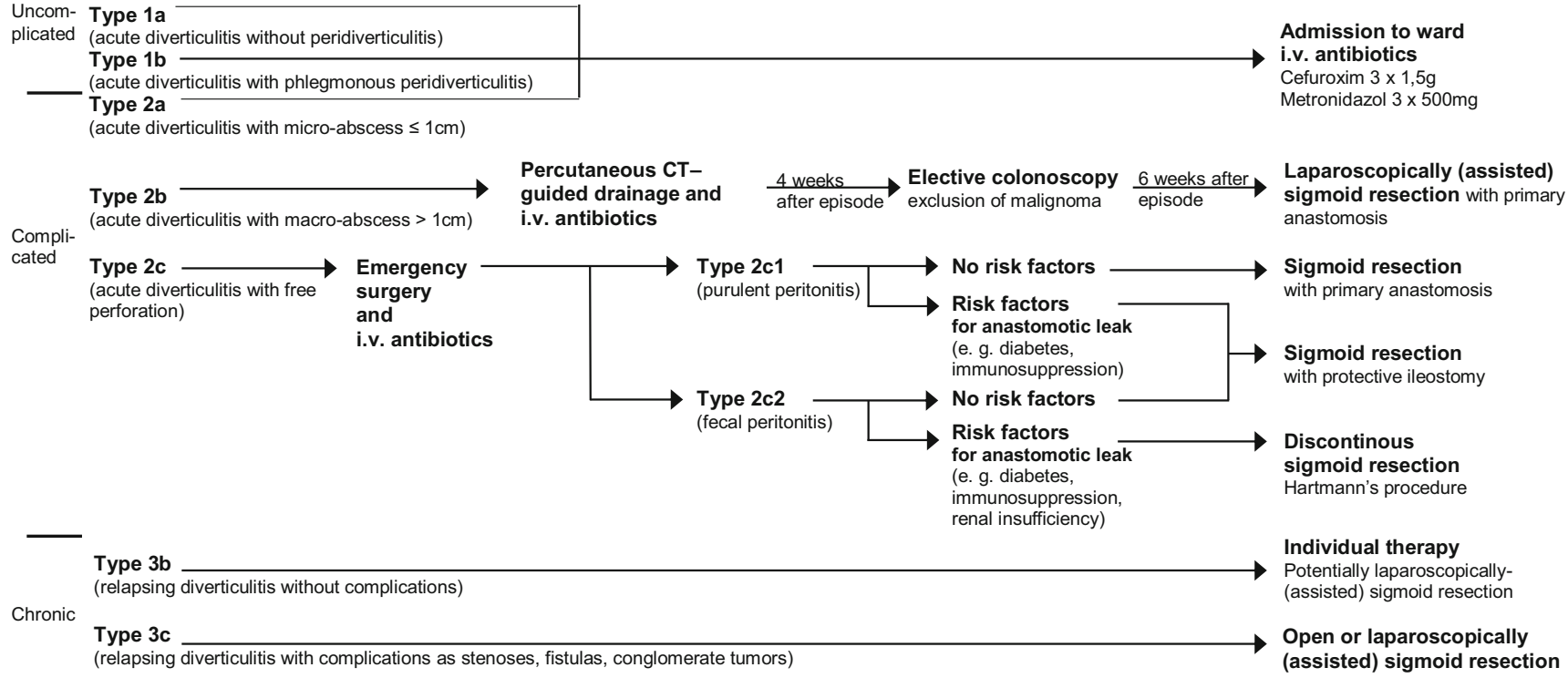
(assisted) sigmoid resection

Fig. 2 Treatment of diverticular disease according to CDD [5, 7] 


\section{Results}

\section{Patient characteristics}

Between November 2013 and September 2015, 190 patients were assessed for eligibility. Eighteen patients declined to participate, and 172 patients were recruited in the two participating centers, 86 respectively. One hundred twenty-three patients $(72 \%)$ could be analyzed in the follow-up 2 years after inclusion. The flow diagram of the VADIS is given in Fig. 3. Table 2 shows the baseline characteristics of the patient cohort.

\section{Comparison type $\mathbf{1 b}$ vs. type $\mathbf{2} \mathbf{a} / \mathbf{b}$}

Patients with acute uncomplicated diverticulitis with phlegmonous peridiverticulitis (type $1 \mathrm{~b}$ ) required less often surgery during the primary stay and early elective interval than patients with acute complicated diverticulitis with microabscess (type $2 \mathrm{a}$ ) or macro-abscess (type $2 \mathrm{~b}$ ): 3 (5\%) vs. 18
(46\%) patients $(p<0.001)$. Twenty patients (46\%) with type $1 \mathrm{~b}$ had recurrent DD within 2 years and ten patients $(36 \%)$ with type $2 \mathrm{a} / \mathrm{b}(p=0.41)$. Eight of 20 patients with type $1 \mathrm{~b}$ and initial conservative treatment had to be operated for recurrence $(40 \%)$ vs. eight/ten patients with type $2 \mathrm{a} / \mathrm{b}(80 \%)(p=0.04)$ (Table 3, Figs. 4 and 5).

No difference between type $1 \mathrm{~b}$ and type $2 \mathrm{a} / \mathrm{b}$ was found in terms of long-term health-related quality of life (SF-36), longterm GIQLI, and long-term gastrointestinal symptoms (Table 3).

\section{Comparison type $2 a$ vs. type $2 b$}

Patients with type 2 a showed a trend to require less surgical treatment during primary stay than patients with type $2 \mathrm{~b}$ : seven $(33 \%)$ vs. eleven $(61 \%)(p=0.08)$. No difference in the rate of recurrence within 2 years was found between type $2 \mathrm{a}$ and $2 \mathrm{~b}$. Three out of five patients with type $2 \mathrm{a}(60 \%)$ and five out of five patients with type $2 \mathrm{~b}(100 \%)$ with recurrent DD needed surgery $(p=0.11)$. All five patients with type $2 \mathrm{~b}$ who were

Fig. 3 Flow diagram of VADIS study

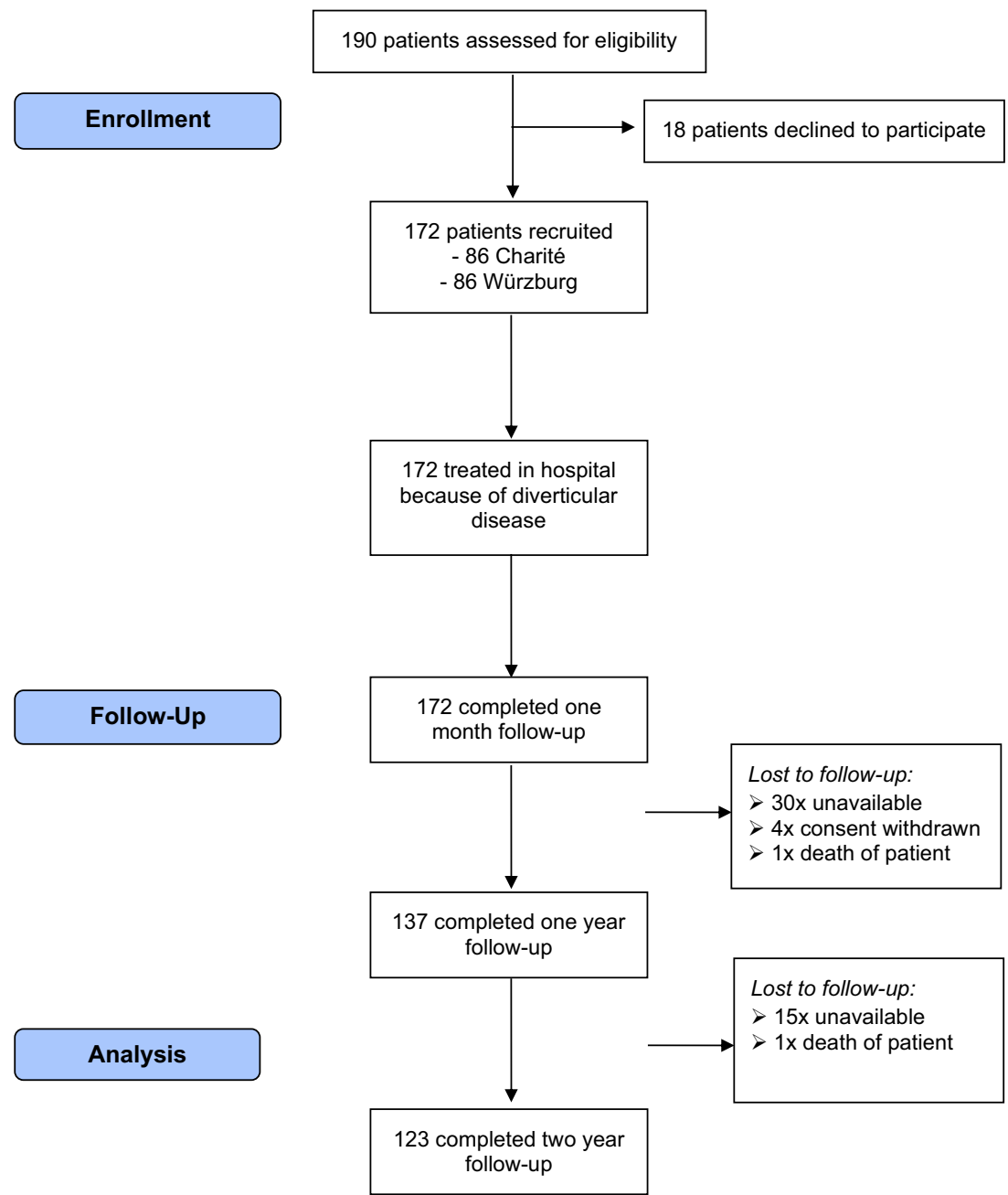


Table 2 Baseline characteristics of patient cohort
Patient cohort $(n=172)$

Sex

Female

$83(48.3 \%)$

Male

$89(51.7 \%)$

Age (years; mean $\pm \mathrm{SD}$ )

$61.0 \pm 13.1$

BMI $\left(\mathrm{kg} / \mathrm{m}^{2} ;\right.$ mean $\left.\pm \mathrm{SD}\right)$

$28.2 \pm 7.0$

Current treatment

Anticoagulants

$34(19.8 \%)$

Glucocorticoids

$17(9.9 \%)$

Other immunosuppressive medication

$3(1.7 \%)$

Radiotherapy within 6 weeks

$2(1.2 \%)$

Chemotherapy within 6 weeks

$3(1.7 \%)$

Current smoking

$38(22.1 \%)$

Alcohol abuse

$5(2.9 \%)$

Comorbidities

$\begin{array}{ll}\text { Coronary artery disease } & 31(18.0 \%)\end{array}$

$\begin{array}{ll}\text { Liver cirrhosis } & 2(1.2 \%)\end{array}$

Chronic obstructive pulmonary disease $\quad 11(6.4 \%)$

$\begin{array}{ll}\text { Diabetes mellitus } & 17(9.9 \%)\end{array}$

$\begin{array}{ll}\text { Malignant disease (current or h/o) } & 15(8.7 \%)\end{array}$

Number of episodes of DD in total (mean \pm SD) $\quad 3.1 \pm 4.8$

Patients with first episode of DD

$74(43.0 \%)$

$\mathrm{CRP}$ at time of admission $(\mathrm{mg} / \mathrm{dl}$; mean $\pm \mathrm{SD})$

$42.8 \pm 62.5$

$\mathrm{CRP} \geq 50 \mathrm{mg} / \mathrm{dl}$ at time of admission

$42(24.4 \%)$

White cell count at time of admission (/nl; mean $\pm \mathrm{SD})$

$11.9 \pm 8.4$

White cell count $>11 / \mathrm{nl}$ or $<4 / \mathrm{nl}$ at time of admission

$83(47.2 \%)$

Clinical examination at presentation

Local peritonism

$61(35.5 \%)$

Generalized peritonism

$16(9.3 \%)$

Abdominal tenderness without peritonism

$95(55.2 \%)$

Classification of diverticular disease

Type 1a

$4(2.3 \%)$

Type $1 \mathrm{~b}$

$56(31.8 \%)$

Type $2 \mathrm{a}$

$21(11.9 \%)$

Type $2 b$

$18(10.2 \%)$

Type $2 \mathrm{c} 1$

$7(4.0 \%)$

Type $2 \mathrm{c} 2$

$0(0 \%)$

Type $3 b$

$54(30.7 \%)$

Type $3 \mathrm{c}$

$12(6.8 \%)$

GIQLI at inclusion (mean \pm SD)

Data are $n(\%)$ or mean $\pm \mathrm{SD}$; Other immunosuppressive medications including methotrexate, azathioprine, and biologicals; alcohol abuse > 15 standard drinks/week. $S D$ standard deviation; $B M I$ body mass index; $h / o$ History of; $D D$ diverticular disease; $C R P$ C-reactive protein; GIQLI Gastrointestinal Quality of Life Index.

initially treated conservatively needed colonic resection due to recurrence (Figs. 4 and 5).

Patients with type 2a had a higher GIQLI-score after 2 years $(123 \pm 15)$ than patients with type $2 \mathrm{~b}(111 \pm 14)(p=$ $0.05)$. Patients with type 2 a performed better in the MCS scale of SF-36 than those with type 2b: $52 \pm 10$ vs. $43 \pm 13$ ( $p=$ 0.04) (Table 4)

\section{Comparison type $3 b$ vs. type $3 c$}

Patients with recurrent diverticulitis without complications (type $3 b$ ) required less often surgery during primary stay than patients with relapsing diverticulitis with complications (type $3 c): 36(67 \%)$ vs. $12(100 \%)(p=0.02)$. The rate of relaparotomy was $8 \%$ in type $3 b$ vs. $25 \%$ in $3 c(p=0.31)$. 
Table 3 Comparison between CDD type $1 \mathrm{~b}$ and type $2 \mathrm{a} / \mathrm{b}$

\begin{tabular}{|c|c|c|c|}
\hline & Type $1 \mathrm{~b}(n=56)$ & Type $2 \mathrm{a} / \mathrm{b}(n=39)$ & $p$ value \\
\hline $\begin{array}{l}\text { Surgery during primary stay or within } \\
\text { eight weeks after first admission (early elective) }\end{array}$ & $3(5.4 \%)$ & $18(46.2 \%)$ & $<0.001 \perp *$ \\
\hline $\begin{array}{l}\text { Length of hospital stay including } \\
\text { readmission to ward (days) }\end{array}$ & $5.6 \pm 4.6$ & $11.3 \pm 7.6$ & $<0.001 * *$ \\
\hline Follow-up after 2 years & 44 & 28 & \\
\hline Recurrence of diverticular disease & $20(45.5 \%)$ & $10(35.7 \%)$ & $0.41 \perp$ \\
\hline Surgery due to recurrence & $8 / 20(40.0 \%)$ & $8 / 10(80.0 \%)$ & $0.04 \perp *$ \\
\hline Admission to ward due to recurrence & $16 / 20(80.0 \%)$ & $8 / 10(80.0 \%)$ & $1.00 \perp$ \\
\hline Abdominal pain after 2 years & & & $0.51 \perp$ \\
\hline Never & $27(61.4 \%)$ & $19(67.9 \%)$ & \\
\hline Rare & $7(15.9 \%)$ & $6(21.4 \%)$ & \\
\hline Sometimes & $8(18.2 \%)$ & $3(10.7 \%)$ & \\
\hline Permanent & $2(4.5 \%)$ & $0(0.0 \%)$ & \\
\hline Bloating after 2 years & & & $0.51 \perp$ \\
\hline Never & $21(47.7 \%)$ & $10(35.7 \%)$ & \\
\hline Rare & $7(15.9 \%)$ & $9(32.1 \%)$ & \\
\hline Sometimes & $12(27.3 \%)$ & $7(25.0 \%)$ & \\
\hline \multirow[t]{2}{*}{ Permanent } & $4(9.1 \%)$ & $2(7.1 \%)$ & \\
\hline & Type $1 \mathrm{~b}(n=44)$ & Type $2 \mathrm{a} / \mathrm{b}(\mathrm{n}=28)$ & $p$ value \\
\hline Painful constipation after two years & & & $0.53^{\perp}$ \\
\hline Never & $32(72.7 \%)$ & $16(57.1 \%)$ & \\
\hline Rare & $6(13.6 \%)$ & $6(21.4 \%)$ & \\
\hline Sometimes & $4(9.1 \%)$ & $3(10.7 \%)$ & \\
\hline Permanent & $2(4.5 \%)$ & $3(10.7 \%)$ & \\
\hline GIQLI at inclusion & $101 \pm 20$ & $100 \pm 20$ & 0.77 \\
\hline GIQLI after 2 years & $121 \pm 16$ & $118 \pm 16$ & 0.50 \\
\hline SF-36/MCS after 2 years & $52 \pm 10$ & $49 \pm 12$ & $0.19=$ \\
\hline SF-36/PCS after 2 years & $46 \pm 10$ & $47 \pm 12$ & 0.79 \\
\hline
\end{tabular}

Data are $n(\%)$ or mean $\pm \mathrm{SD}$; CDD Classification of Diverticular Disease; SD standard deviation; GIQLI Gastrointestinal Quality of Life Index; SF-36 Short Form 36 Health Survey; MCS mental component summary; $P C S$ physical component summary. ${ }^{\perp}$ Chi-square test; * $p \leq 0.05 ; \cdot T$ test for independent variables

Seventeen (41\%) patients with type 3b suffered from recurrence of DD, while eight were treated with sigmoid colectomy (Fig. 6). None of the patients with type $3 \mathrm{c}$ had relapse of DD.

Patients with type $3 b$ tended to have lower scores in GIQLI after 2 years than those with type $3 \mathrm{c}: 110 \pm 21$ vs. $128 \pm 9$ ( $p=$ 0.07). Patients classified as type $3 \mathrm{~b}$ scored less in the "General Health" scale of SF-36 than those classified as type 3c: $60 \pm$ 22 vs. $83 \pm 8(p=0.04)$. The same applied to the "Mental Health" scale of the SF-36: $70 \pm 20$ vs. $91 \pm 11(p=0.04)$ (Table 5).

\section{Comparison of surgical and conservative treatment in CDD}

There was neither a difference between the surgical and conservative treatment of patients with type $2 \mathrm{a}$ in terms of recurrence of DD, GIQLI-scores, gastrointestinal symptoms after 2 years, nor long-term quality of life in SF-36 (Table 6).
Surgically treated patients with macro-abscess (type 2b) reached higher scores in the "Social Functioning" scale of the SF-36 after 2 years than conservatively treated patients: $91 \pm 12$ vs. $47 \pm 21(p=0.002)$ (Table 6).

Fewer patients with type $3 \mathrm{~b}$ who underwent sigmoid colectomy suffered from bloating (67\% vs. $100 \% ; p=0.01)$ and painful constipation (30\% vs. $73 \% ; p=0.006)$ than those with conservative treatment. Patients after surgery trended to have less abdominal pain after 2 years $(37 \%$ vs. $67 \% ; p=$ 0.06) (Table 6).

\section{Operative procedure and postoperative complications}

Laparoscopic sigmoid resection with primary anastomosis was done in 41 cases, laparoscopic converted to open sigmoid resection with primary anastomosis was done in 13 cases, open sigmoid resection with primary anastomosis was 
Fig. 4 Treatment of patients with CDD type $2 \mathrm{a}$ after 2 years

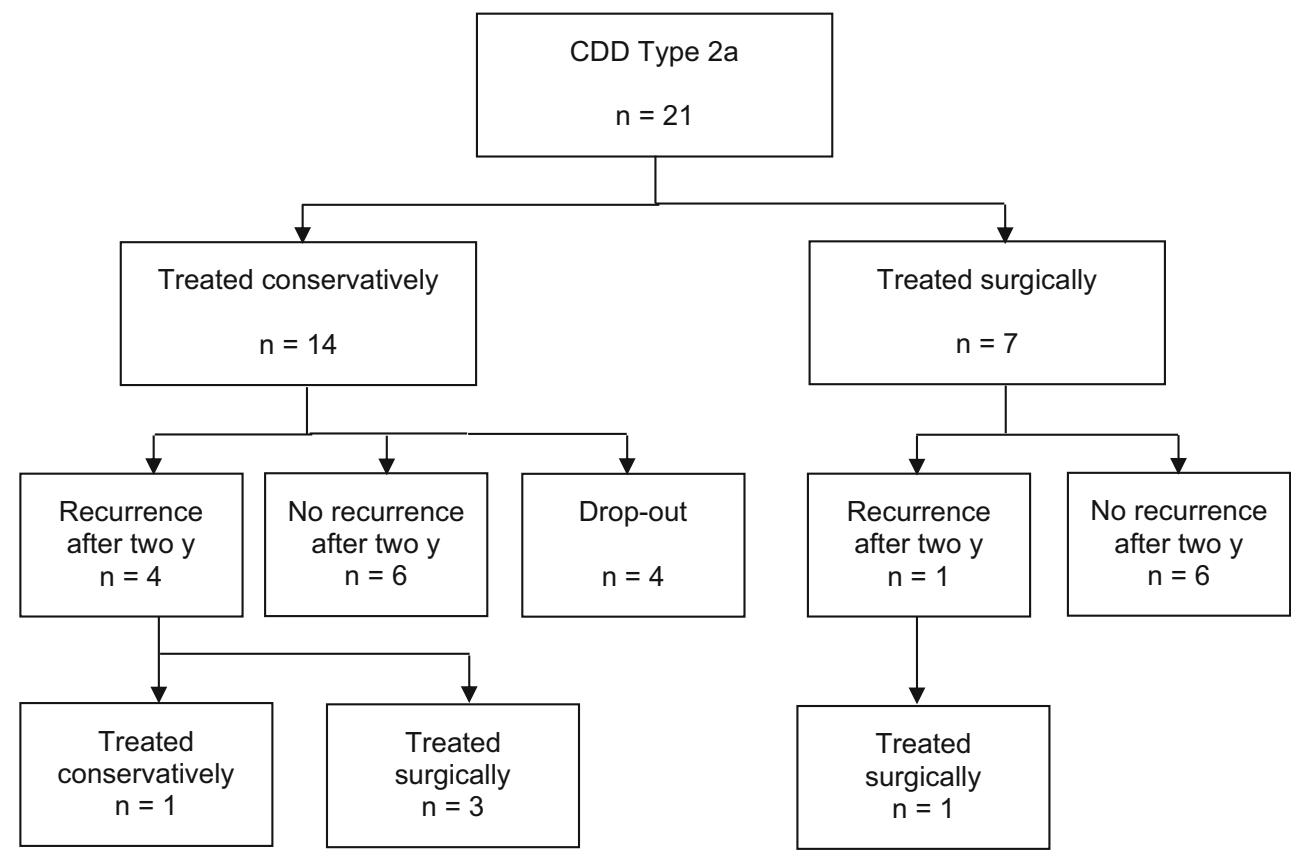

performed in 43 cases, and open Hartmann resection in three cases. There was no 30-day postoperative mortality in all types of CDD. The rate of anastomotic leakage was seven/ $79(9 \%)$ in primarily operated patients and in none out of 23 patients who were operated with recurrent DD. Severe perioperative complications (Clavien-Dindo $\geq 3$ ) occurred in twelve/79 (15\%) patients who were operated primarily and in none out of $23(0 \%)$ patients who were operated due to recurrent disease.

Fig. 5 Treatment of patients with CDD type $2 b$ after 2 years

\section{Discussion and conclusions}

Despite the high prevalence of DD, a uniform international classification and convincing evidence about the optimal treatment strategy are missing to date. As there are different types including acute uncomplicated and complicated DD and chronic recurrent DD, the recent German guideline for DD aims to give a comprehensive classification system and therapeutic outline [5-7].

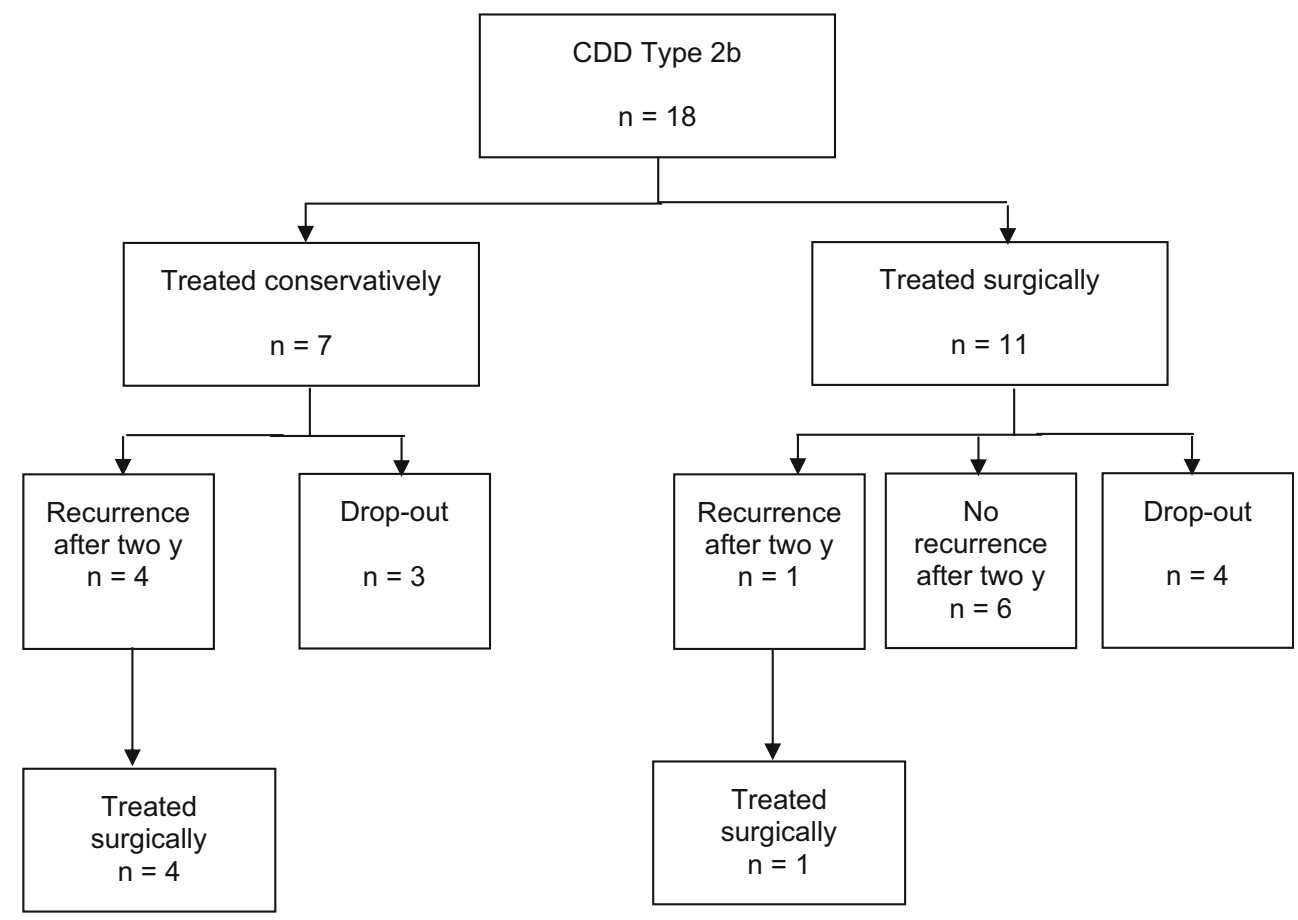


Table 4 Comparison between CDD type $2 a$ and type $2 b$

\begin{tabular}{|c|c|c|c|}
\hline & Type $2 \mathrm{a}(n=21)$ & Type $2 b(n=18)$ & $p$ value \\
\hline $\begin{array}{l}\text { Surgery during primary stay or within } \\
\text { eight weeks after first admission (early elective) }\end{array}$ & $7(33.3 \%)$ & $11(61.1 \%)$ & $0.08 \perp$ \\
\hline Length of hospital stay including readmission to ward (days) & $8.5 \pm 4.7$ & $14.6 \pm 9.1$ & $0.01 * *$ \\
\hline Follow-up after 2 years & 17 & 11 & \\
\hline Recurrence of diverticular disease & $5(29.4 \%)$ & $5(45.5 \%)$ & $0.39 \perp$ \\
\hline Surgery due to recurrence & $3 / 5(60.0 \%)$ & $5 / 5(100.0 \%)$ & $0.11 \perp$ \\
\hline Admission to ward due to recurrence & $3 / 5(60.0 \%)$ & $5 / 5(100.0 \%)$ & $0.11 \perp$ \\
\hline Abdominal pain after 2 years & & & $0.12^{\perp}$ \\
\hline Never & $14(82.4 \%)$ & $5(45.5 \%)$ & \\
\hline Rare & $2(11.8 \%)$ & $4(36.4 \%)$ & \\
\hline Sometimes & $1(5.9 \%)$ & $2(18.2 \%)$ & \\
\hline Permanent & $0(0.0 \%)$ & $0(0.0 \%)$ & \\
\hline GIQLI at inclusion & $102 \pm 18$ & $99 \pm 22$ & $0.63 \cdot$ \\
\hline GIQLI after 2 years & $123 \pm 15$ & $111 \pm 14$ & 0.05 \\
\hline SF-36/MCS after 2 years & $52 \pm 10$ & $43 \pm 13$ & $0.04 * *$ \\
\hline SF-36/PCS after 2 years & $46 \pm 12$ & $49 \pm 10$ & $0.53 \cdot$ \\
\hline
\end{tabular}

Data are $n(\%)$ or mean $\pm \mathrm{SD}$; CDD Classification of Diverticular Disease; SD standard deviation; GIQLI Gastrointestinal Quality of Life Index; $S F-36$ Short Form 36 Health Survey; MCS mental component summary; $P C S$ physical component summary. ${ }^{\perp}$ Chi-square test; $* p \leq 0.05 ; \cdot T$ test for independent variable
This was the first prospective study to evaluate the German CDD. We could show that the majority of patients with acute phlegmonous diverticulitis without abscess (type 1b) can be treated conservatively without adverse short-term and longterm outcomes. It seems justified to classify these patients as uncomplicated. The VADIS study detected differences between patients with micro-abscess (type 2a) and macro- abscess (type $2 \mathrm{~b}$ ). While all patients with type $2 \mathrm{~b}$ required surgery, the majority of patients with micro-abscess could be treated conservatively and were not in need of colectomy during follow-up. What is more, the long-term quality of life of patients with macro-abscess was worse. As far as chronic recurrent diverticulitis is concerned, patients with type $3 \mathrm{~b}$ had a favorable long-term course with less gastrointestinal
Fig. 6 Treatment of patients with CDD type $3 \mathrm{~b}$ after 2 years

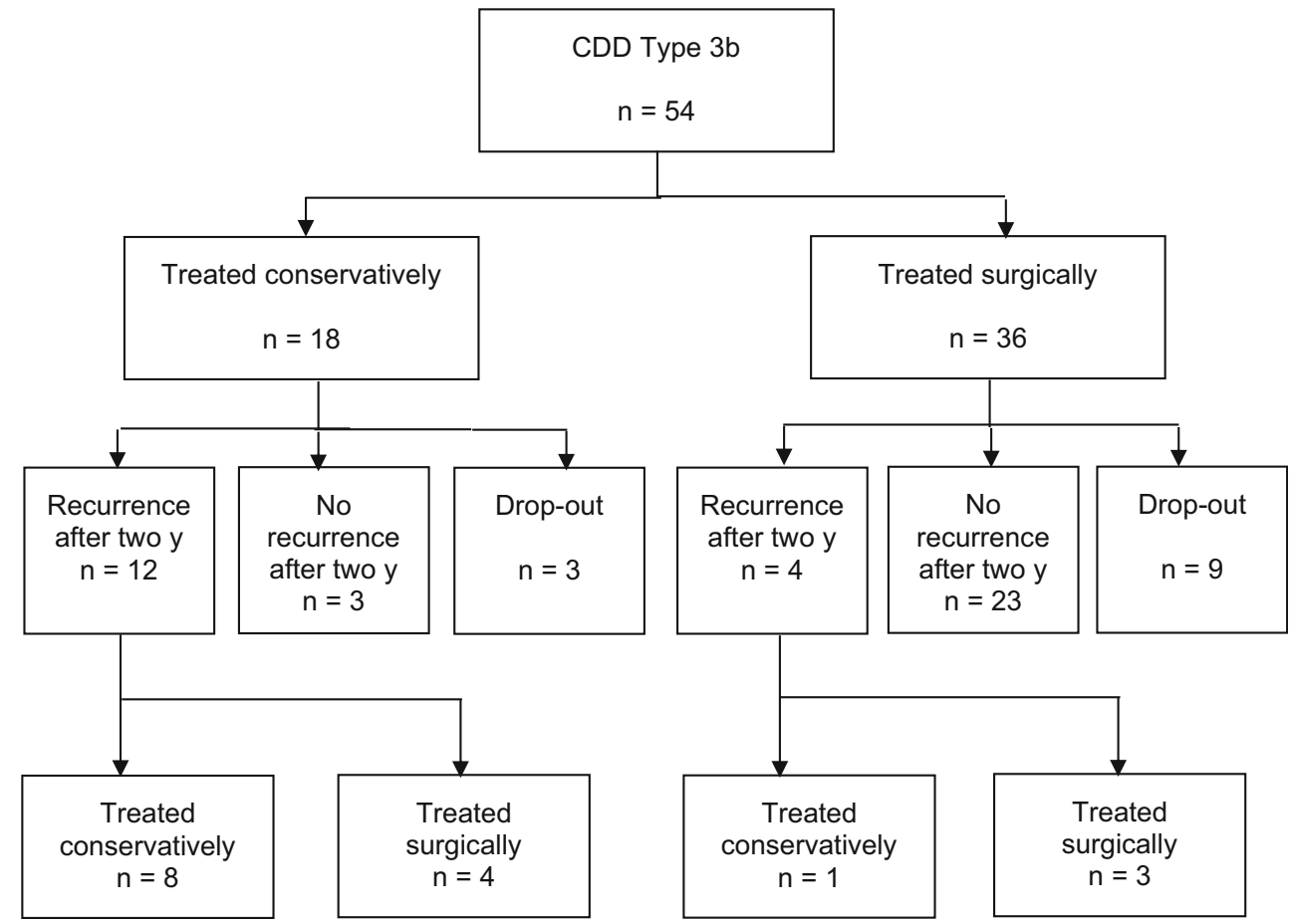


Table 5 Comparison between CDD type $3 \mathrm{~b}$ and type $3 \mathrm{c}$

\begin{tabular}{|c|c|c|c|}
\hline & Type $3 \mathrm{~b}(n=54)$ & Type $3 \mathrm{c}(n=12)$ & $p$ value \\
\hline Surgery during primary stay or within eight weeks after first admission (early elective) & $36(66.7 \%)$ & $12(100.0 \%)$ & $0.02 \perp *$ \\
\hline Length of hospital stay including readmission to ward (days) & $10.6 \pm 6.8$ & $19.3 \pm 10.1$ & $0.008 * *$ \\
\hline Follow-up after 2 years & 42 & 4 & \\
\hline Recurrence of diverticular disease & $16(38.1 \%)$ & $0(0.0 \%)$ & $0.13^{\perp}$ \\
\hline Surgery due to recurrence & $7 / 16(43.8 \%)$ & $0 / 0(0.0 \%)$ & $0.38 \perp$ \\
\hline Admission to ward due to recurrence & $11 / 16(68.9 \%)$ & $0(0.0 \%)$ & $0.23 \perp$ \\
\hline Abdominal pain after 2 years & & & $0.12^{\perp}$ \\
\hline Never & $22(51.2 \%)$ & $4(100.0 \%)$ & \\
\hline Rare & $8(18.6 \%)$ & $0(0.0 \%)$ & \\
\hline Sometimes & $7(16.3 \%)$ & $0(0.0 \%)$ & \\
\hline Permanent & $6(14.0 \%)$ & $0(0.0 \%)$ & \\
\hline GIQLI at inclusion & $87 \pm 21$ & $100 \pm 22$ & $0.08 \cdot$ \\
\hline GIQLI after 2 years & $110 \pm 21$ & $128 \pm 9$ & $0.07 \cdot$ \\
\hline SF-36/MCS after 2 years & $48 \pm 11$ & $58 \pm 4$ & $0.08 \cdot$ \\
\hline SF-36/PCS after 2 years & $48 \pm 10$ & $54 \pm 2$ & $0.004 * *$ \\
\hline SF-36/general health after 2 years & $60 \pm 22$ & $83 \pm 8$ & $0.04 * *$ \\
\hline SF-36/mental health after 2 years & $70 \pm 20$ & $91 \pm 11$ & $0.04 * *$ \\
\hline
\end{tabular}

Data are $n(\%)$ or mean $\pm \mathrm{SD}$; CDD Classification of Diverticular Disease; SD standard deviation; GIQLI Gastrointestinal Quality of Life Index; $S F$-36 Short Form 36 Health Survey; MCS mental component summary; PCS Physical component summary. ${ }^{\perp}$ Chi-square test; ${ }^{*} p \leq 0.05 ; \cdot T$ test for independent variable

complaints after surgery compared with conservative management.

The recent guidelines for DD recommend conservative treatment of type $1 \mathrm{~b}$ without sigmoid resection in the diseasefree interval [5]. In the VADIS study, patients with type $1 \mathrm{~b}$ required primary surgery in less than $5 \%$, whereas patients with types $2 \mathrm{a} / \mathrm{b}$ did more often $(46 \%)$. Patients with type $1 \mathrm{~b}$ needed less often surgery in the long-term course due to recurrence than types $2 \mathrm{a} / \mathrm{b}: 40 \%$ vs. $80 \%$. In both groups - type $1 \mathrm{~b}$ and types $2 \mathrm{a} / \mathrm{b}$ - the number of patients with recurrent DD within 2 years was high (46\% and $36 \%$ ). In a retrospective cohort analysis, $48 \%$ of patients suffered from recurrence after conservative treatment, of whom $86 \%$ were classified to stage Hinchey I - mild cases of diverticulitis such as phlegmon or small abscess [12]. The rate of recurrence may depend on the severity of DD [5]. Retrospective data is heterogenous with rates of nearly $2 \%$ after uncomplicated diverticulitis [13] and 35\% after complicated DD; of these, $16 \%$ were subsequently operated [14].

According to VADIS, in type $1 \mathrm{~b}$, gastrointestinal symptoms did not differ regardless of whether patients had been operated during primary stay or not. Brandlhuber et al. found in their retrospective study that patients with type $1 \mathrm{~b}$ had lower scores on the GIQLI when they were operated, more pain in the lower left abdomen, and more frequent diverticulosis-associated complaints after surgery [15]. Holmer et al. showed that the conservative treatment of phlegmonous diverticulitis led to a nearly complete regression of inflammation in histology [16].
Another novelty in CDD is the differentiation between type $2 \mathrm{a}$ and type $2 \mathrm{~b}$. All patients with type $2 \mathrm{~b}$ who were not operated primarily developed recurrence which needed to be operated. Patients with type $2 \mathrm{~b}$ showed a trend in having worse long-term GIQLI. In addition, their mental health score in SF36 was worse compared with type $2 \mathrm{a}$. Brandlhuber et al. showed that patients with type $2 \mathrm{a}$ had more diverticulosisassociated symptoms and worse health-related quality of life when they were operated [15]. VADIS trial did not find any difference between the conservative and surgical treatment of type $2 \mathrm{a}$. Patients with micro-abscess may therefore be treated conservatively. Surgically treated patients with macro-abscess showed better "Social Functioning" in SF-36. Taken together, VADIS provides evidence that patients with type $2 b$ DD may be operated initially in contrast to patients with type $2 \mathrm{a}$. It appears useful to differentiate acute diverticulitis according to abscess size because these types differ in terms of treatment and outcome. This is in accordance with the findings of Brandlhuber et al. After being operated, patients with type $2 \mathrm{~b}$ suffered less from pain in the lower left abdomen and less frequently from diverticulosis-associated symptoms than those without operation [15].

Another new aspect of CDD is the subdivision of chronic recurrent DD (types $3 \mathrm{a} / \mathrm{b} / \mathrm{c}$ ). VADIS showed that the differentiation between type $3 \mathrm{~b}$ and type $3 \mathrm{c}$ is reasonable. Recurrent diverticulitis with complications is a more severe disease and surgery is more demanding than in type $3 \mathrm{~b}$. Twenty-five percent of patients with type $3 \mathrm{c}$ underwent a relaparotomy. On 
Table 6 Subgroup analysis of CDD and association between quality of life after 2 years and primary treatment

\begin{tabular}{|c|c|c|c|c|}
\hline CDD & Follow-up after 2 years & $\begin{array}{l}\text { Treated primarily } \\
\text { surgically }(n=44)\end{array}$ & $\begin{array}{l}\text { Treated primarily } \\
\text { conservatively }(n=70)\end{array}$ & $p$ value \\
\hline \multirow[t]{7}{*}{ Type 2a } & Total patients $(n)$ & 7 & 10 & 0.24 \\
\hline & GIQLI & $128 \pm 10$ & $119 \pm 17$ & 0.24 \\
\hline & SF-36/physical functioning & $88 \pm 22$ & $69 \pm 32$ & 0.18 \\
\hline & SF-36/social functioning & $93 \pm 19$ & $85 \pm 18$ & 0.39 \\
\hline & Abdominal pain & $1(14.3 \%)$ & $2(20.0 \%)$ & 0.76 \\
\hline & Bloating & $4(57.1 \%)$ & $5(50.0 \%)$ & 0.77 \\
\hline & Painful constipation & $3(42.9 \%)$ & $4(40.0 \%)$ & 0.91 \\
\hline \multirow[t]{7}{*}{ Type $2 b$} & Total patients $(n)$ & 7 & 4 & \\
\hline & GIQLI & $115 \pm 13$ & $104 \pm 16$ & 0.23 \\
\hline & SF-36/physical functioning & $83 \pm 22$ & $64 \pm 43$ & 0.34 \\
\hline & SF-36/social functioning & $91 \pm 12$ & $47 \pm 21$ & $0.002 *$ \\
\hline & Abdominal pain & $3(42.9 \%)$ & $3(75.0 \%)$ & 0.30 \\
\hline & Bloating & $5(71.4 \%)$ & $4(100.0 \%)$ & 0.24 \\
\hline & Painful constipation & $3(42.9 \%)$ & $2(50.0 \%)$ & 0.82 \\
\hline \multirow[t]{7}{*}{ Type 3b1.1.1.1.1.1. } & Total patients $(n)$ & 27 & 15 & \\
\hline & GIQLI & $110 \pm 21$ & $107 \pm 24$ & 0.65 \\
\hline & SF-36/physical functioning & $80 \pm 21$ & $77 \pm 26$ & 0.64 \\
\hline & SF-36/social functioning & $84 \pm 20$ & $81 \pm 25$ & 0.63 \\
\hline & Abdominal pain & $10(37.0 \%)$ & $10(66.7 \%)$ & 0.07 \\
\hline & Bloating & $18(66.7 \%)$ & $15(100.0 \%)$ & $0.01 *$ \\
\hline & Painful constipation & $8(29.6 \%)$ & $11(73.3 \%)$ & $0.006^{*}$ \\
\hline
\end{tabular}

Data are mean \pm standard deviation or $n(\%)$; CDD Classification of Diverticular Disease; GIQLI Gastrointestinal Quality of Life Index; SF-36 Short Form 36 Health Survey; ${ }^{*} p \leq 0.05 . \cdot T$ test for independent variables

the other hand, there was a trend towards patients with type $3 \mathrm{c}$ having higher scores in GIQLI after 2 years compared with type $3 \mathrm{~b}$. Patients with type $3 \mathrm{c}$ assessed their general state of health and their mental health better after 2-year follow-up. Evidence is provided that types $3 b$ and $3 c$ are indeed different entities of DD. Whereas type 3c seems to have a longer and more complicated postoperative course, type $3 \mathrm{~b}$ appears to have a more unfavorable long-term course with more recurrences, more gastrointestinal symptoms, and worse quality of life.

Interestingly, patients with type $3 \mathrm{~b}$ benefitted from sigmoid colectomy. Surgically treated patients had less bloating and less painful constipation after 2 years. These results are confirmed in other studies. A multicenter randomized trial revealed that patients with recurrent or ongoing abdominal complaints after an episode of diverticulitis benefitted from an elective sigmoid resection compared to conservative therapy, resulting in a higher GIQLI at 6 months' follow-up [17]. In a retrospective study, $89 \%$ of patients with chronic uncomplicated diverticulitis - requiring a minimum of 3 months of clinical symptoms or radiographic signs - benefitted from surgery with acceptable morbidity rates [18].

According to the German guideline for DD, type $3 \mathrm{~b}$ should be operated only after a careful assessment of risks and benefits depending on the clinical symptoms $[5,6]$. In view of the results of VADIS, the indication for sigmoid resection in patients with type $3 \mathrm{~b}$ may be extended and patients should be informed that colon resection may be associated with less long-term gastrointestinal symptoms.

Several potential limitations of the trial must be taken into account. First, it was an observational trial without randomization. All patients were prospectively recruited with regular and close follow-up. Second, recurrences of DD were not again classified according to CDD. The severity of recurrent DD could be estimated by the treatment of recurrent disease. The same criteria for $\mathrm{DD}$ were again required for the diagnosis of recurrence. Since not all patients were hospitalized for recurrence and treated in one of the two study centers, the rate of recurrence may have been overestimated. The somewhat high rate of recurrences after surgical treatment of DD might also be caused by this phenomenon.

The VADIS study provides evidence that the German Classification of Diverticular Disease (CDD) is feasible and allows differentiation into types of diverticulitis which leads to appropriate treatment. Surgery for recurrence was not associated with more complications than primary surgery. Other trials confirmed that recurrences do not imply higher risk of complications compared with the first episode $[12,19]$. 
CDD classifies type $1 \mathrm{~b}$ correctly as uncomplicated diverticulitis which should be treated conservatively. The differentiation in micro-abscess and macro-abscess is justified as patients with macro-abscess require surgery while patients with micro-abscess may be treated conservatively in the majority of cases with success. The long-term quality of life of patients with macro-abscess was worse compared with patients with micro-abscess. Considering recurrences and long-term quality of life, patients with macro-abscess benefitted from primary elective sigmoid colectomy. Evidence was provided that patients with relapsing diverticulitis without complications may benefit from elective sigmoid colectomy which appears to reduce long-term gastrointestinal symptoms.

Authors' contributions Priv. Doz. Dr. med. Johannes C. Lauscher: study conception and design, acquisition of data, interpretation of data, drafting and revising the article, final approval of the version to be published, and agreement to be accountable for all aspects of the work.

Priv. Doz. Dr. med. Johann F. Lock: study conception and design, acquisition of data, interpretation of data, drafting and revising the article, final approval of the version to be published, and agreement to be accountable for all aspects of the work.

Katja Aschenbrenner: acquisition of data, drafting and revising the article, final approval of the version to be published, agreement to be accountable for all aspects of the work

Rahel M. Strobel: interpretation of data, drafting and revising the article, final approval of the version to be published, and agreement to be accountable for all aspects of the work.

Marja Leonhardt: acquisition of data, drafting and revising the article, final approval of the version to be published, and agreement to be accountable for all aspects of the work.

Andrea Stroux: interpretation of data, statistical analysis, revising the article, final approval of the version to be published, and agreement to be accountable for all aspects of the work.

Priv. Doz. Dr. med. Benjamin Weixler: interpretation of data, drafting and revising the article, final approval of the version to be published, and agreement to be accountable for all aspects of the work.

Prof. Dr. med. Christoph-Thomas Germer: study conception and design, acquisition of data, interpretation of data, drafting and revising the article, final approval of the version to be published, and agreement to be accountable for all aspects of the work.

Prof. Dr. med. Martin E. Kreis: study conception and design, acquisition of data, interpretation of data, drafting and revising the article, final approval of the version to be published, and agreement to be accountable for all aspects of the work.

Funding Open Access funding provided by Projekt DEAL. No grant support was received for this study. Internal resources of the departments involved were used.

Data availability All original data and material is available and can be provided to the journal on request.

\section{Compliance with ethical standards}

Conflict of interest The authors declare that they have no conflicts of interest.

Ethics approval The study protocol was approved by the Ethics Committee of the Charité - University Medicine Berlin (Application No. EA4/092/13).
Clinical trial registration The VADIS trial is registered at "Deutsches Register Klinischer Studien" https://www.drks.de (ID: DRKS00005576). Date of registration: December 16, 2013.

Consent to participate All participants gave their signed informed consent prior to inclusion.

Code availability not applicable

Open Access This article is licensed under a Creative Commons Attribution 4.0 International License, which permits use, sharing, adaptation, distribution and reproduction in any medium or format, as long as you give appropriate credit to the original author(s) and the source, provide a link to the Creative Commons licence, and indicate if changes were made. The images or other third party material in this article are included in the article's Creative Commons licence, unless indicated otherwise in a credit line to the material. If material is not included in the article's Creative Commons licence and your intended use is not permitted by statutory regulation or exceeds the permitted use, you will need to obtain permission directly from the copyright holder. To view a copy of this licence, visit http://creativecommons.org/licenses/by/4.0/.

\section{References}

1. Jun S, Stollman N (2002) Epidemiology of diverticular disease. Best Pract Res Clin Gastroenterol 16(4):529-542

2. Ritz J-P, Gröne J, Engelmann S, Lehmann KS, Buhr HJ, Holmer C (2013) What is the actual benefit of sigmoid resection for acute diverticulitis? : Functional outcome after surgical and conservative treatment. Chirurg 84(8):673-680

3. Hinchey EJ, Schaal PG, Richards GK (1978) Treatment of perforated diverticular disease of the colon. Adv Surg 12:85-109

4. Klarenbeek BR, de Korte N, van der Peet DL, Cuesta MA (2012) Review of current classifications for diverticular disease and a translation into clinical practice. Int J Color Dis 27(2):207-214

5. Leifeld L, Germer CT, Böhm S, Dumoulin FL, Häuser W, Kreis M (2014) u. a. [S2k guidelines diverticular disease/diverticulitis]. Z Gastroenterol 52(7):663-710

6. Kruis W, Germer C-T, Leifeld L (2014) German Society for Gastroenterology, Digestive and Metabolic Diseases and The German Society for General and Visceral Surgery. Diverticular disease: guidelines of the German Society for Gastroenterology, Digestive and Metabolic Diseases and the German Society for General and Visceral Surgery. Digestion. 90(3):190-207

7. Schreyer AG, Layer G, German Society of Digestive and Metabolic Diseases (DGVS) as well as the German Society of General and Visceral Surgery (DGAV) in collaboration with the German Radiology Society (DRG) (2015) S2k Guidlines for Diverticular Disease and Diverticulitis: Diagnosis, Classification, and Therapy for the Radiologist. Rofo 187(8):676-684

8. World Medical Association (2013) World Medical Association Declaration of Helsinki: ethical principles for medical research involving human subjects. JAMA 310(20):2191-2194

9. von Elm E, Altman DG, Egger M, Pocock SJ, Gøtzsche PC, Vandenbroucke JP (2014) u. a. The Strengthening the Reporting of Observational Studies in Epidemiology (STROBE) statement: guidelines for reporting observational studies. Int J Surg Lond Engl 12(12):1495-1499

10. Eypasch E, Williams JI, Wood-Dauphinee S, Ure BM, Schmülling C, Neugebauer E (1995) u. a. Gastrointestinal Quality of Life Index: development, validation and application of a new instrument. Br J Surg 82(2):216-222 
11. Bullinger M (1995) German translation and psychometric testing of the SF-36 Health Survey: preliminary results from the IQOLA Project. International Quality of Life Assessment. Soc Sci Med 41(10):1359-1366

12. Klarenbeek BR, Samuels M, van der Wal MA, van der Peet DL, Meijerink WJ, Cuesta MA (2010) Indications for elective sigmoid resection in diverticular disease. Ann Surg 251(4):670-674

13. Salem TA, Molloy RG, O’Dwyer PJ (2007) Prospective, five-year follow-up study of patients with symptomatic uncomplicated diverticular disease. Dis Colon Rectum 50(9):1460-1464

14. Moreno AM, Wille-Jørgensen P (2007) Long-term outcome in 445 patients after diagnosis of diverticular disease. Color Dis 9(5):464 468

15. Brandlhuber M, Genzinger C, Brandlhuber B, Sommer WH, Müller MH, Kreis ME (2018) Long-term quality of life after conservative treatment versus surgery for different stages of acute sigmoid diverticulitis. Int J Color Dis 33(3):317-326

16. Holmer C, Lehmann KS, Engelmann S, Frericks B, Loddenkemper C, Buhr HJ (2010) u. a. Microscopic findings in sigmoid diverticulitis-changes after conservative therapy. J Gastrointest Surg 14(5):812-817

17. van de Wall BJM, Stam MAW, Draaisma WA, Stellato R, Bemelman WA, Boermeester MA (2017) u. a. Surgery versus conservative management for recurrent and ongoing left-sided diverticulitis (DIRECT trial): an open-label, multicentre, randomised controlled trial. Lancet Gastroenterol Hepatol 2(1):13-22

18. Boostrom SY, Wolff BG, Cima RR, Merchea A, Dozois EJ, Larson DW (2012) Uncomplicated diverticulitis, more complicated than we thought. J Gastrointest Surg 16(9):1744-1749

19. Ritz J-P, Lehmann KS, Frericks B, Stroux A, Buhr HJ, Holmer C (2011) Outcome of patients with acute sigmoid diverticulitis: multivariate analysis of risk factors for free perforation. Surgery. 149(5):606-613

Consent for publication

The manuscript is not submitted for publication elsewhere.

Publisher's note Springer Nature remains neutral with regard to jurisdictional claims in published maps and institutional affiliations.

\section{Affiliations}

\section{Johannes C. Lauscher ${ }^{1}$ (D) $\cdot$ Johan F. Lock $^{2} \cdot$ Katja Aschenbrenner $^{1} \cdot$ Rahel M. Strobel $^{1} \cdot$ Marja Leonhardt $^{3}$. Andrea Stroux $^{4,5} \cdot$ Benjamin Weixler $^{1} \cdot$ Christoph-Thomas Germer $^{2} \cdot$ Martin E. Kreis $^{1}$}

1 Department of General, Visceral and Vascular Surgery, Charité Campus Benjamin Franklin, Hindenburgdamm 30, 12203 Berlin, Germany

2 Department of General, Visceral, Transplantation, Vascular and Pediatric Surgery, University Hospital of Würzburg, Oberdürrbacher Straße 6, 97080 Würzburg, Germany

3 Innlandet Hospital Trust, Norwegian National Advisory Unit on Concurrent Substance Abuse and Mental Health Disorders, Brumunddal, Norway
4 Institute of Biometry and Clinical Epidemiology, Charité Universitätsmedizin Berlin, Freie Universität Berlin, HumboldtUniversität zu Berlin and Berlin Institute of Health, Charitéplatz 1, 10117 Berlin, Germany

5 Berlin Institute of Health (BIH), Anna-Louisa-Karsch 2, 10178 Berlin, Germany 